\title{
State of Shocks Synchronization among Members of the GCC
}

\author{
Ashraf Nakibullah $^{1}$ \\ ${ }^{1}$ Arab Open University - Bahrain Branch, Bahrain \\ Correspondence: Dr. Ashraf Nakibullah, Arab Open University - Bahrain Branch, P. O. Box: 18211, Bahrain. Tel: \\ 973-3985-7520. \\ Received: December 19, 2016 \\ Accepted: January 4, 2017 \\ Online Published: April 26, 2017 \\ doi:10.5430/rwe.v8n1p15 \\ URL: https://doi.org/10.5430/rwe.v8n1p15
}

\begin{abstract}
This paper examines fluctuations of aggregate supply and demand shocks across the GCC countries. It argues that the world oil price influences aggregate demand and supply of these countries. Thus, in contrast to other studies, a SVAR model is used to identify structural shocks by including the oil price. The aggregate supply and demand shocks are then analyzed. The correlations of supply shocks among the member countries are either negative or low positive. Similarly, the correlations of demand shocks, except few pairs of countries, are also negative and low positive. Thus, shocks are not synchronized. These results are different than the results found in other similar studies probably due to the model specification. The implication of the findings is that the GCC countries would find it difficult to adjust supply and demand shocks if they form their aspired Gulf Monetary Union.
\end{abstract}

Keywords: shocks synchronization, Gulf Monetary Union, structural VAR

\section{Introduction}

The European Monetary Union has served as the catalyst for the worldwide existing and aspiring monetary union (MU) where a single (common) currency prevails among the members of the union. Weighing costs against benefits have been the guiding principles of forming a union. The main benefit from common currency arises from the increased intraregional trade among the member countries of the union (Rose, 2000, Rose, 2009, Santos Silva and Tenreyro, 2010). The main cost of adhering to common currency arises from sacrificing the monetary autonomy of the individual member countries. Different member countries may hit by a different (asymmetric) shocks due to different stages of development in which case some countries may need of an expansionary monetary policy while other members may require contractionary policy. Therefore, the presence of asymmetric shocks constitutes costs of the MU (see, for example, Houssa, 2008, for details). Such costs from asymmetric shocks may outweigh the benefits of a union where intraregional trade is small as in the case of the six Gulf Cooperation Council (GCC) countries (Bahrain, Kuwait, Oman, Qatar, Saudi Arabia and the UAE) who have been considering for a monetary union for a long time now. Thus, researchers on MU have devoted a considerable effort in determining whether shocks among the member countries are synchronized. If shocks are synchronized, costs of forming a MU would be lower.

Since its formation in 1981, the GCC countries aspired to form Gulf Monetary union (Shebeb, 2016). It took twenty years to take some steps in 2001 in harmonizing their economic policies so that the Gulf Monetary union (GMU) could be formed in 2010 (see, for example, Shebeb, 2016, for details of the steps). However, as we now know that the GMU has not been formed but their efforts remain active. To make the problem worst, Oman (in 2006) and the UAE (in 2009) have pulled out of the GMU for the time being.

The IMF is one of the first to endorse the GMU (Fasano, 2003). Based on convergence criteria regarding inflation, real GDP, fiscal and monetary policy, and external sector found in the traditional Optimal Currency Areas (Mundell, 1961), it argues that some progress has already been achieved toward economic integration among the GCC countries. It also advocates the potential benefits that could be achieved by forming the GMU. However, discussions are all descriptive based on some graphs and tables on vital macroeconomic variables (Fasano, 2003).

Abu-Qarn and Abu-Bader (2008) offer more serious econometric study on the suitability of forming GMU. They have used two variables structural vector autoregressive (SVAR) model to generate structural shocks in real GDP and the GDP deflator. If shocks are significantly positively correlated, shocks are said to be symmetric (or synchronized) otherwise they are asymmetric. They find demand shocks are in general symmetric but, more importantly, supply shocks are asymmetric and conclude against the forming of GMU because in that case costs 
would outweigh whatever small benefits it may bring. Louis, Balli and Osman (2012) using SVAR models as in Abu-Qarn and Abu-Bader (2008) (but breaking the aggregate supply in oil GDP and non-oil GDP) find that non-oil GDP shocks are weakly symmetrical across the GCC countries. Based on their finding of asymmetric shocks, studies conducted on the suitability of forming viable GMU come to the general conclusion that the GCC countries are far from forming the GMU (Benbouziane, Benhabbib, and Benamaar, 2010, Kandil and Trabelsi, 2012, and Alshehry and Slimane, 2013, among others).

This paper reexamines the viability of the GMU using a SVAR model to identify the aggregate supply and demand shocks and examines the correlations of the supply and demand shocks among the member countries of the GCC. However, this study differs from previous studies mentioned above in some major ways. These are oil-exporting countries. All their economic activities evolve around this hydrocarbon sector. Their aggregate demand and aggregate supply depends very much on the world oil market and oil price. Majority of the government current revenues (about $80 \%$ on average) of the GCC countries comes from the hydrocarbon sector (Espinoza and Senhadji, 2011). Governments are the major employers and investors in these countries. Thus, shocks generated without this sector (as the common feature of those studies mentioned above) would imply ignoring the reality. This paper includes the world oil price as one of the variables in our SVAR model. We also include foreign partners' price and nominal exchange rates as separate variables in the model. The suppliers of imported goods (foreign countries) to keep their market shares may manipulate their prices so that the exchange rates and foreign prices may move in the opposite direction that may render no exchange rates pass-through to the domestic prices. Thus, we include the exchange rates and foreign prices as two separate variables in our SVAR model. We use CPI (as a measure of price level and inflation) rather than GDP deflator as feature of the many studies mentioned above. This is because policy makers in the GCC countries (as in other countries) react to CPI inflation. Finally, our data extend to the most recent (2014) data available avoiding data from 1960s and early 1970s when these countries were just gaining independence and data were not reliable (Summers and Heston, 1991).

Next section discusses two main aggregates, namely, inflation and output growth of the GCC countries and their correlations over the period 1976-2014. Section 3 describes empirical methodology. Data sources and empirical results are presented in section 4. Section 5 concludes the paper.

\section{Output Growth and Inflation Correlations among the GCC Countries}

As mentioned above, the theory of the optimum currency areas requires countries to fulfill some convergence criteria (such as similar inflation rates, economic development, budget deficits and debt relative to the GDP) before forming a monetary union. This is because, for example, countries in a union may face asymmetric growths, then individual member countries under monetary union with common currency would not be able to handle through monetary policy. Similarly, a slow-growing country would put strain on the fast-growing country when they form monetary union (Houssa, 2008). Thus, similarities of growth rates among the aspiring member countries are conducive to form a monetary union. Inflation concern is another fundamental issue in forming a union. However, this may not be an issue for the GCC countries because traditionally these are low inflationary countries though they experienced a little higher than the trend inflation in recent years. This section shows how the growth rates and inflation of the GCC countries are correlated with each other and with the aggregate inflation and the aggregate output of the GCC countries. Following Beyer, Doomik, and Hendry (2001), the aggregate inflation and growth rate of the GCC countries are calculated as follows:

$$
\Delta x_{t}=\sum_{i=1}^{6} w_{i, t-1} \Delta x_{i, t} \quad w_{i, t}=\frac{G D P_{i, t}}{\sum_{i=1}^{6} G D P_{i . t}}
$$

where $x_{i, t}$ is the natural logarithm of the CPI or the real GDP of a GCC country $i, \Delta x_{t}$ is the aggregate inflation rate or aggregate growth rate of the GCC countries and GDP is the real GDP of a GCC country $i$. Thus, aggregate inflation or growth rate in equation (1) is the weighted sum of the inflations or growth rates of the GCC countries where weights are the lagged real GDP shares.

Annul data from 1975 to 2014 (the latest data available) for the CPI are taken from the International Financial Statistics (IFS) and the GDP from World Economic Outlook (WEO). Figure 1 shows the performance of inflation and real GDP growth of the GCC countries. It shows the correlations of each GCC country's inflation and growth rate with the aggregate inflation and output growth of the GCC countries. Figure 1 and table 1 show that inflation of each GCC country is highly correlated with the aggregate GCC inflation. Bahrain has the lowest and Saudi Arabia 
has the highest correlation. This is because Bahrain and Saudi Arabia has the lowest and highest GDP share, respectively, in aggregate inflation. Though similarities inflation is conducive to form monetary union, seigniorage loss could be an issue for some GCC countries if they form the GMU. Buiter (2008) argues that different inflation rates may be optimal for different GCC countries because these countries differ in the effectiveness of tax administration.

Different picture arises regarding the correlation of the output growth. Figure 1 and table 2 shows that the growth rate of Oman is negatively correlated with Kuwait, Qatar and Saudi Arabia and with aggregate GCC growth rate. This may be a blessing in disguise as Oman has already pulled out of the GMU. Moreover, correlations for any pair of countries are low and insignificant. Saudi Arabia has correlation near one (0.91) with the GCC aggregate which reflects the high share (more than 50\%) in aggregate output growth. Thus, we may conclude though the inflation fluctuations have been similar, output fluctuations have been quite dissimilar which may be costly for a possible GMU. We examine more about this in next sections.

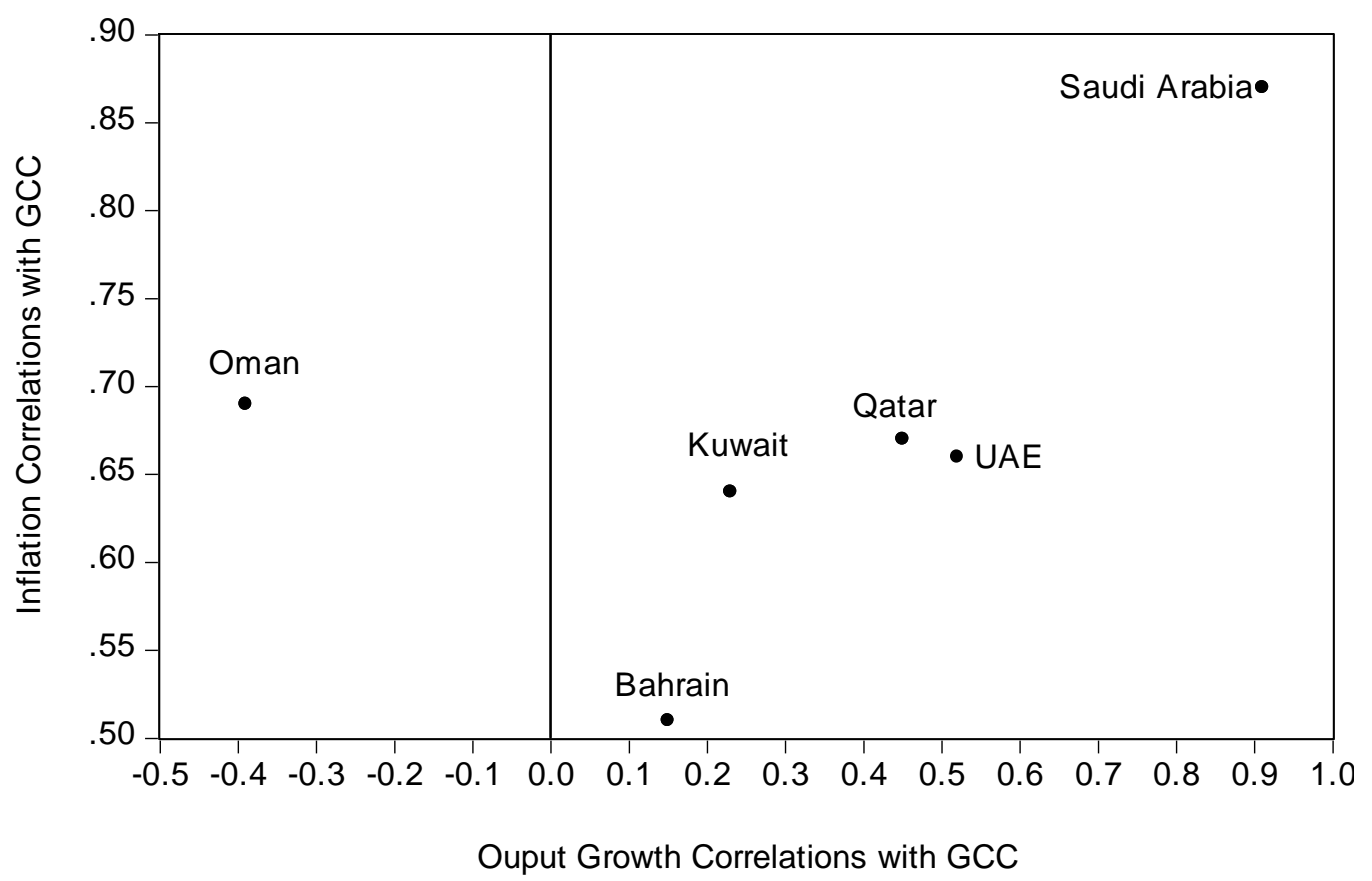

Figure 1. Correlation of inflation and output growth with GCC

Table 1. Correlation matrix of inflation

\begin{tabular}{llllllll}
\hline \hline & Bahrain & Kuwait & Oman & Qatar & Saudi Arabia & UAE & GCC \\
Bahrain & 1.00 & & & & & & \\
Kuwait & $0.43^{* *}$ & 1.00 & & & & & \\
Oman & 0.20 & $0.59^{* *}$ & 1.00 & & & & \\
Qatar & $0.30^{*}$ & $0.32^{*}$ & $0.43^{* *}$ & 1.00 & & & \\
Saudi Arabia & $0.48^{* *}$ & $0.60^{* *}$ & $0.52^{* *}$ & $0.29^{*}$ & 1.00 & & \\
UAE & $0.38^{* *}$ & 0.20 & $0.43^{* *}$ & $0.79^{* *}$ & 0.24 & 1.00 & \\
GCC & $0.51^{* *}$ & $0.64^{* *}$ & $0.69^{* *}$ & $0.67^{* *}$ & $0.87^{* *}$ & $0.66^{* *}$ & 1.00 \\
\hline \hline
\end{tabular}

Note: ** significant at $5 \%$ or less level and * significant between $5 \%$ and $10 \%$ level. 
Table 2. Correlation matrix of output growth

\begin{tabular}{llllllll}
\hline \hline & Bahrain & Kuwait & Oman & Qatar & Saudi Arabia & UAE & GCC \\
Bahrain & 1.00 & & & & & & \\
Kuwait & 0.26 & 1.00 & & & & & \\
Oman & 0.18 & -0.24 & 1.00 & & & & \\
Qatar & 0.26 & $0.36^{* *}$ & -0.23 & 1.00 & & & \\
Saudi Arabia & 0.04 & -0.04 & -0.43 & 0.27 & 1.00 & & \\
UAE & 0.08 & 0.01 & 0.12 & 0.09 & 0.26 & 1.00 & \\
GCC & 0.15 & 0.23 & -0.39 & $0.45^{* *}$ & $0.91^{* *}$ & $0.52^{* *}$ & 1.00 \\
\hline \hline
\end{tabular}

Note: ** significant at $5 \%$ or less level and * significant between $5 \%$ and $10 \%$ level.

\section{Empirical Specification}

A SVAR is used to identify aggregate supply and demand shocks by utilizing the long-run identifying restrictions as in Blanchard-Quah (1989). Since these are oil-based economies and they heavily depend on imported goods including construction and industrial raw materials, oil price and foreign partners' prices are important determinants of their aggregate supply and demand. The five variables included in the model are the nominal effective exchange rate (NEER), oil price, foreign trading partners' price level, real GDP, and CPI. All variables are expressed in natural logarithm. Thus, we denote $e_{t}=\ln (\mathrm{NEER}), \quad p o_{t}=\ln$ (oil price), $p_{t}^{*}=\ln$ (foreign trading partners' CPI), $y_{t}=\ln \left(\right.$ real GDP) and $p_{t}=\ln (\mathrm{CPI})$. Nakibullah (2016) explains in details about the roles of oil price and the ordering of the five variables. Let $z$ is the vector of five dependent variables ordered as $\left[e_{t}, p o_{t}, p_{t}^{*}, y_{t}, p_{t}\right]$. Various unit root tests on levels of all five variables (not shown here) show that they are nonstationary, however, they are all first difference stationary $I(1)$. The first differences of these variables can be represented as an infinite moving average as follows:

$$
\Delta z_{t}=A_{0} u_{t}+A_{1} u_{t-1}+A_{2} u_{t-2}+\ldots \ldots \ldots
$$

where $\Delta$ is the first difference operator, $u$ is the vector of five ( nominal exchange rate, oil price, foreign price, real output, and CPI) structural shocks [ordered $u_{e}, u_{p o}, u_{p^{*}}, u_{y}, u_{p}$ ], and $A_{i}$ are $5 \times 5$ matrices representing the impulse response functions of the shocks to the elements of $\Delta z$. The following finite reduced-form VAR is first estimated.

$$
\Delta z_{t}=B_{1} \Delta z_{t-1}+B_{2} \Delta z_{t-2}+\ldots \ldots . .+B_{q} \Delta z_{t-q}+\varepsilon_{t}
$$

where $\varepsilon$ is the vector of residuals [ordered $\varepsilon_{e}, \varepsilon_{p o}, \varepsilon_{p^{*}}, \varepsilon_{y}, \varepsilon_{p}$ ] obtained from estimating equation (2), $B^{\prime} s$ are estimated coefficients and $q$ is the optimal lag length that ensures white noise residuals $\varepsilon_{t}$. Note equation (3) can be represented as the following infinite moving average process

$$
\Delta z_{t}=\varepsilon_{t}+C_{1} \varepsilon_{t-1}+C_{t} \varepsilon_{t-2}+\ldots \ldots \ldots
$$


where $C_{0}$ is by definition is set to identity matrix. We assume that there exists a non-singular matrix $R$ such that

$$
\varepsilon_{t}=R u_{t}
$$

Restrictions are needed to identify the elements of $R$ so that we can recover structural shocks $u_{t}$ from the regression residuals $\varepsilon_{t}$. One of the restrictions is that the structural shocks are orthonormal, that is, its covariance matrix is an identity matrix $E\left(u_{t} u_{t}^{\prime}\right)=I$. Matrix $R$ is still not identified and we need to add more restrictions. There is a more or less agreement that oil prices move with the change in the exchange rates (see, for example, Nakibullah, 2016, and the World Bank, 2014, for details). Thus, the first restriction is that exchange rate shocks can only affect oil prices in the long-run. Then it is reasonable to assume that only exchange rate and oil price shocks can have a long-run impact on foreign prices. The exchange rate, oil price, and foreign price shocks would have a long-run impact on domestic supply, and finally all these shocks and domestic supply shocks can affect domestic consumer prices. After recovering or identifying the shocks, we examine the correlations of the aggregate supply and demand shocks.

\section{Empirical Results}

As mentioned above the annul data used in this study covering the period from 1975 to 2014 and they are taken from IFS and WEO. Sources, construction and measures of the data are discussed in details in Nakibullah (2016). Figures 2 and 3 display the aggregate supply demand shocks generated from the SVAR model described in the previous section.

Consider first the supply shocks in figure 1. These are oil-based economies. Schaechter (2003) claims (without evidence) that these countries face symmetric shocks because, being oil exporting countries, oil price changes would affect all the GCC countries in a similar way. However, the fluctuations in the shocks (figure 1) in last four decades tell the different story. There are marked differences in the fluctuations in each country. For example, there were major increases in oil price in late seventies, mid-eighties, and middle part of the last decade. On the other hand, there were major slumps in oil price in the end of eighties, nineties and at the end of the last decade. In general oil price increase raises the firms' production costs reflecting mainly in the foreign trading partners' prices that would have an adverse effect on supply shock. Oil price increase also increases the oil revenues of these countries and with it capital investment and productivity increase. This couple with direct supply effect would outweigh the adverse supply effect. However, this did not happen for all countries. It only happened for Bahrain and, especially, for Saudi Arabia in the late seventies. The negative supply shock has been substantially reduced for all countries with the increased oil price in the mid-eighties. We also observe that positive supply shock is not uniform for all countries in most part of the last decade when there was an unprecedented increase in oil price. Except in eighties, negative and positive shocks, do not match for most of the countries. Figure 2 also shows a huge positive shock for Kuwait following the Gulf or Kuwait war in 1990-91. 

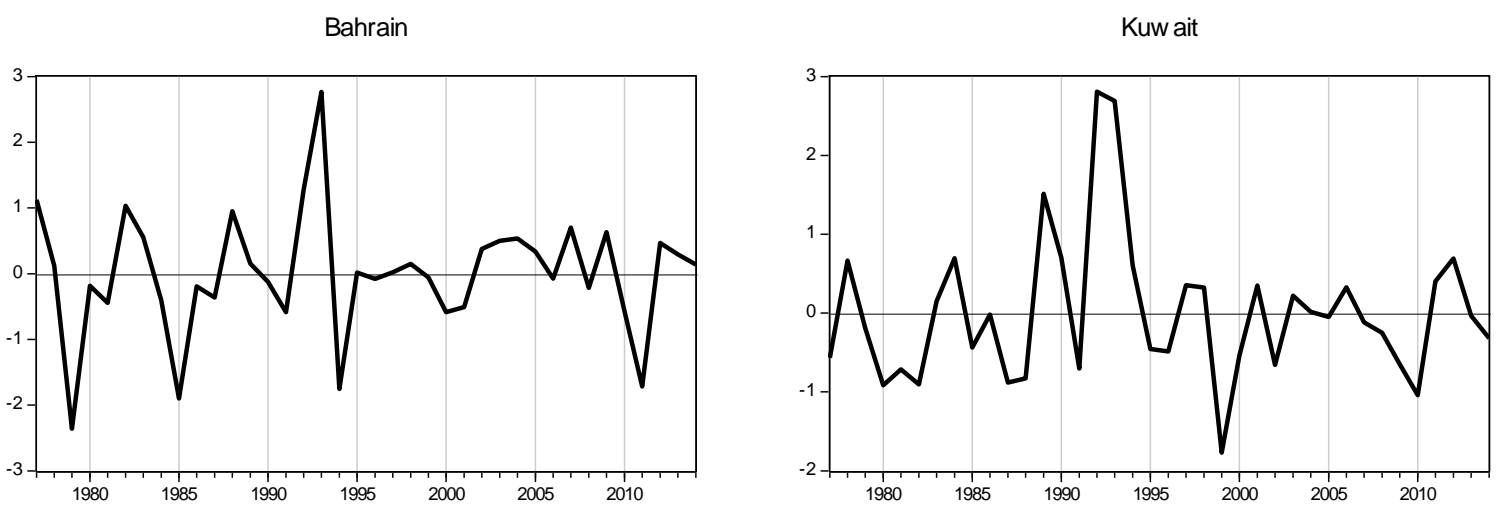

Oman

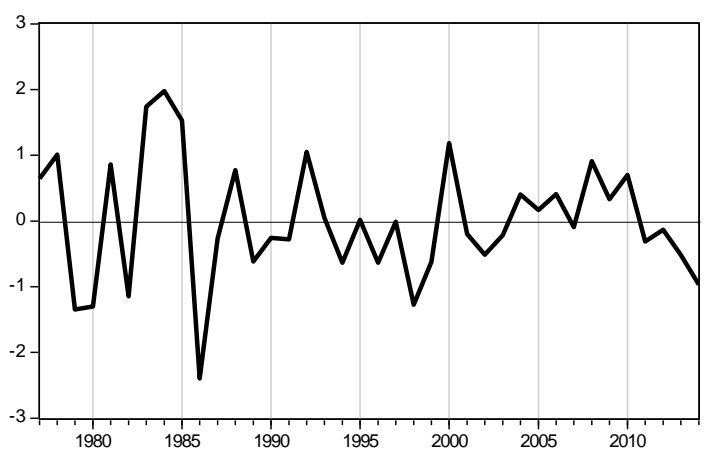

Qatar

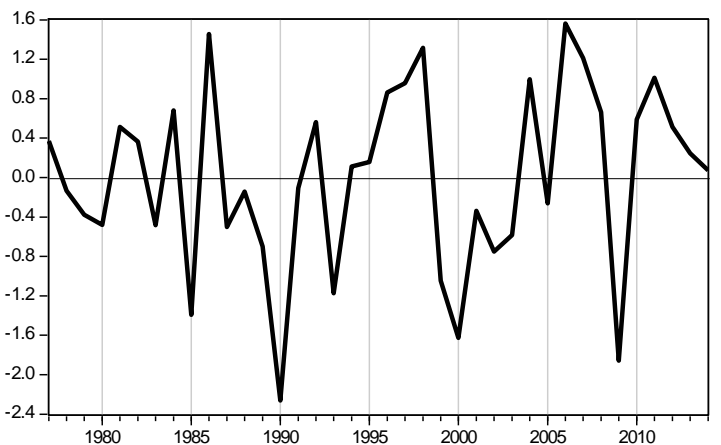

Saudi Arabia

UAE
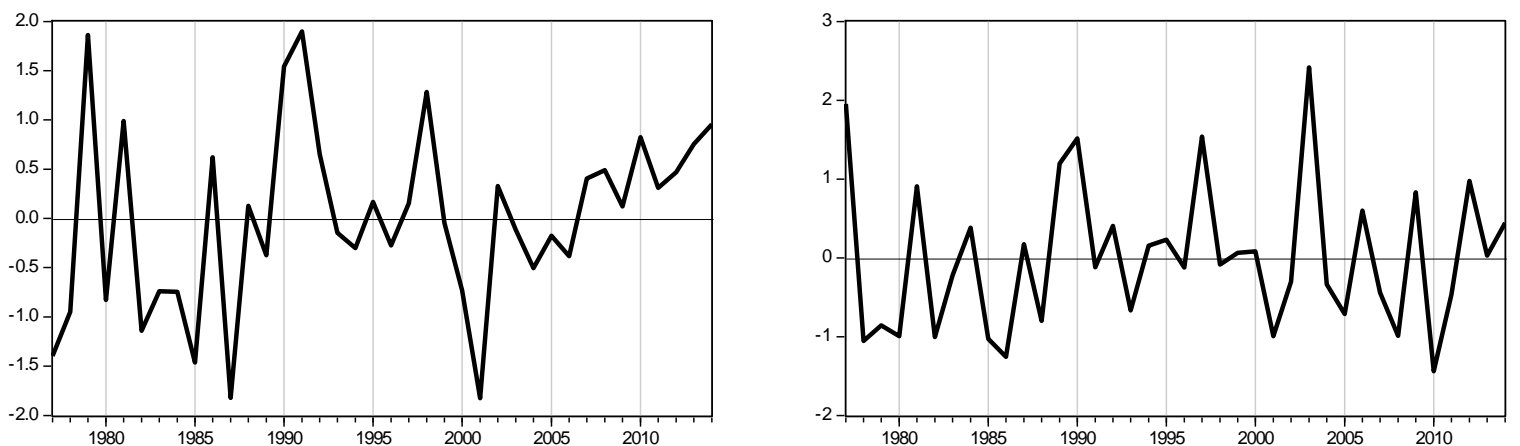

Figure 2. Supply shocks

Figure 3 displays the demand shocks. Like supply shocks, there seems no similarities among demand shocks. For example, Bahrain and the UAE experienced huge negative demand shocks in 1990 while Oman experienced positive demand shock. Similarly, Kuwait and the UAE experienced negative demand shocks while Saudi Arabia experienced positive shock in 1995. Most interesting are the dissimilarities of the demand shocks in the last decade when most of the decade had unprecedented high oil price. 
Bahrain

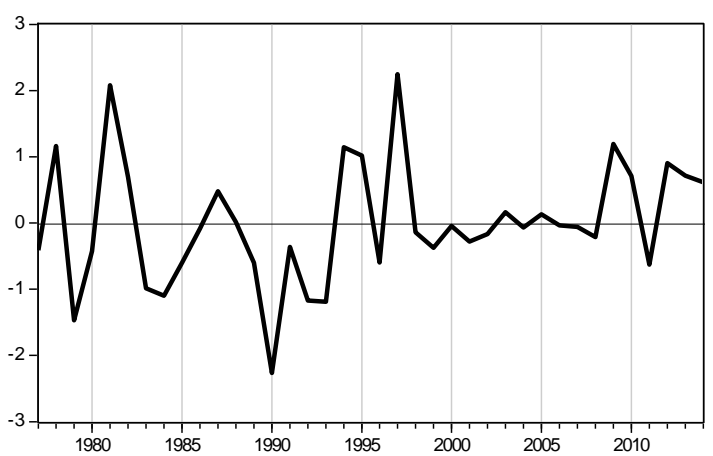

Oman

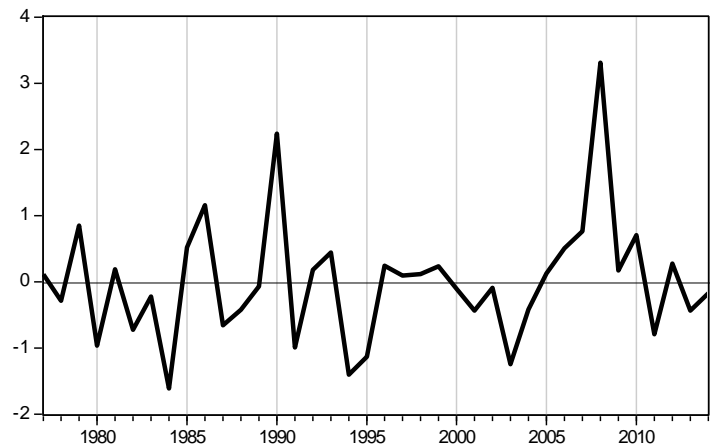

Saudi Arabia

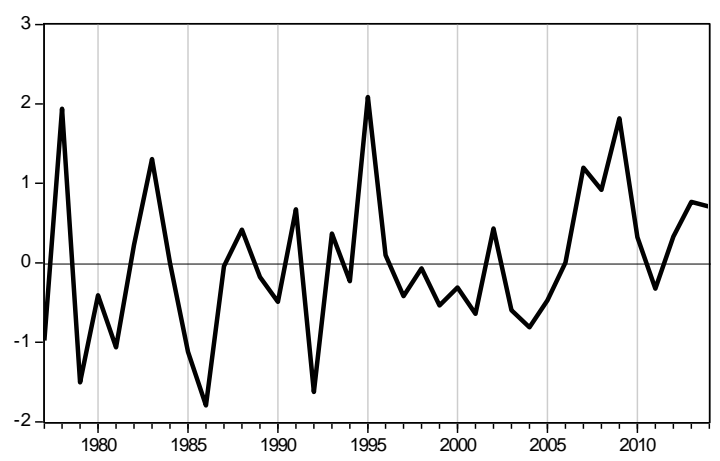

Kuw ait

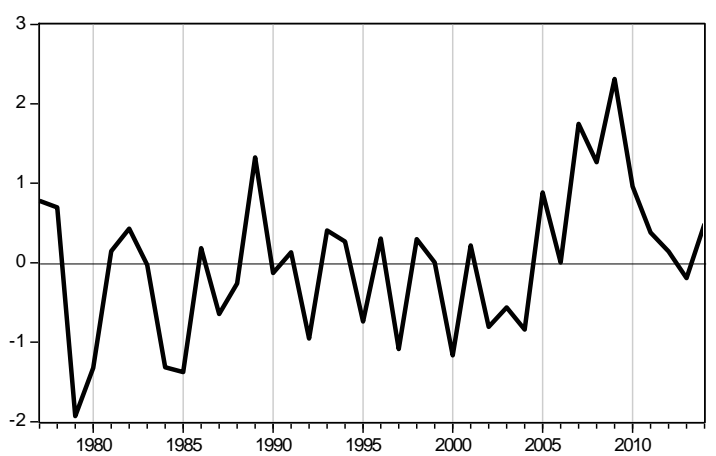

Qatar

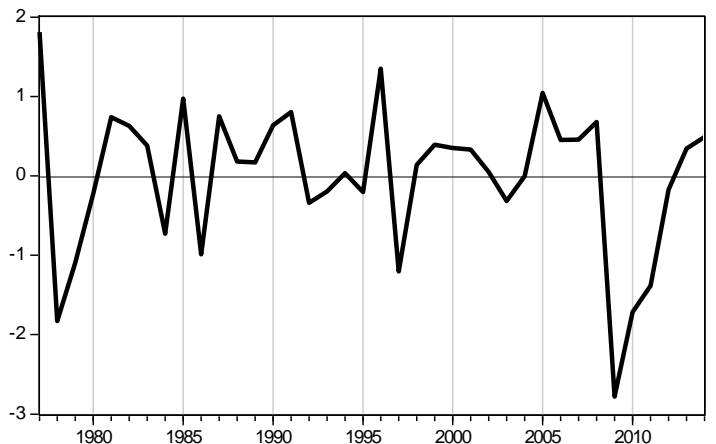

UAE

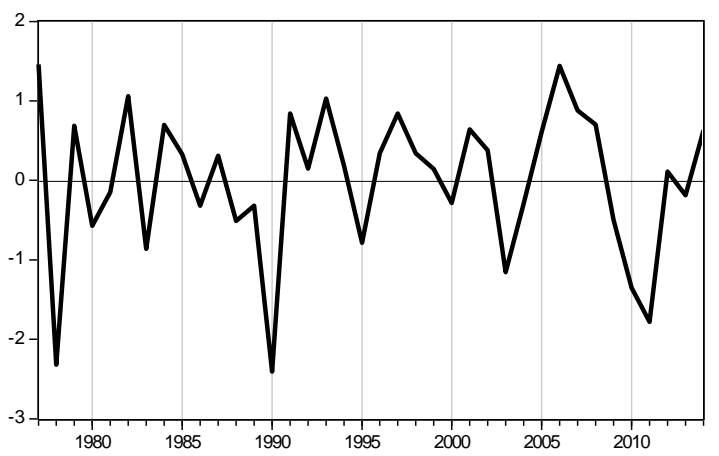

Figure 3. Demand Shocks

Monetary policy of these countries is basically to maintain stable prices by managing liquidity that fluctuates with the fluctuating oil price (Nakibullah, 2011). They are successful in this regard as these are low inflation countries. Demand shocks are mainly associated with fiscal policy shocks. These countries have no income tax. Government spending is mainly financed by oil revenues. Thus, their aggregate demand and supply directly related to the oil price. Depending on their preferences, oil price induced government spending affects differently their demands for non-oil GDP products and their nominal prices. Thus, it is not surprising that demand shocks hit differently for different GCC countries. Figure 3 shows Kuwait, Oman, Saudi Arabia and the UAE in the last decade experienced huge positive demand shocks when the aggregate demand increased with the increased oil price. Oil price induced increased international reserve fed into rapid money and credit growth that led to a accelerated inflation during that period (Sturm et al., 2008).

Table 3 shows the correlation of matrices of aggregate supply shocks. Correlations of supply shocks among the GCC countries are quite dismal as is evident in figure 1. Only supply shocks of Bahrain and Kuwait are correlated at $5 \%$ level but the size $(0.32)$ of the correlation is not remarkable. Most of the correlations are close to zero and many of 
them are negatively correlated. That is, shocks are asymmetric which is not conducive to form a monetary union. Table 4 shows the correlation of matrices of aggregate demand shocks.

Table 3. Correlation matrix of supply shocks

\begin{tabular}{lllllll}
\hline \hline & Bahrain & Kuwait & Oman & Qatar & Saudi Arabia & UAE \\
Bahrain & 1.00 & & & & & \\
Kuwait & $0.32^{*}$ & 1.00 & & & & \\
Oman & 0.09 & 0.13 & 1.00 & & & \\
Qatar & -0.01 & 0.06 & -0.14 & 1.00 & & \\
Saudi Arabia & -0.11 & 0.06 & -0.31 & 0.13 & 1.00 & \\
UAE & 0.19 & 0.18 & 0.09 & -0.12 & 0.07 & 1.00 \\
\hline \hline
\end{tabular}

Note: * Significant at $10 \%$ level.

Table 4. Correlation matrix of demand shocks

\begin{tabular}{lllllll}
\hline \hline & Bahrain & Kuwait & Oman & Qatar & Saudi Arabia & UAE \\
Bahrain & 1.00 & & & & & \\
Kuwait & 0.21 & 1.00 & & & & \\
Oman & -0.25 & 0.29 & 1.00 & & & \\
Qatar & -0.23 & -0.06 & 0.09 & 1.00 & & \\
Saudi Arabia & $0.30^{*}$ & $0.44^{* *}$ & -0.11 & -0.20 & 1.00 & \\
UAE & 0.02 & -0.02 & 0.02 & $0.45^{* *}$ & -0.19 & 1.00 \\
\hline \hline
\end{tabular}

Note: ** Significant at $5 \%$ and $*$ significant at $10 \%$ level.

Though the demand correlations are little better but they are still dismal contrary to the results found in some other studies (see, for example, Abu-Qarn and Abu-Bader, 2008, and Kandil and Trabelsi, 2012). Except between Bahrain-Saudi Arabia, Kuwait-Saudi Arabia, and Qatar-UAE, all correlations are either negative or close to zero. Studies that found symmetric demand shocks did not include oil price in their model. That was a gross omission given that all economic activities of these countries evolve around this sector.

\section{Conclusion}

The GCC countries have aspired to form the Gulf Monetary Union (GMU) for a long time. However, they took a concrete steps in 2001 to form the GMU by 2010 . However, it did not materialize yet. Since their announcement in 2001, researchers have engaged in viability of the GMU in terms of benefits and costs of the GMU. Because they are oil exporting countries, oil price changes are expected to affect all GCC countries in a similar way. In other words, these countries would face symmetric shocks (Schaechter, 2003). Abu-Qarn and Abu-Bader (2008) provide first serious empirical study regarding shocks synchronization of the GCC countries. Their two variables (real GDP and GDP deflator) SVAR model fails to recognize the role of oil price in the determination of aggregate demand and supply shocks. They conclude that supply shocks are not synchronized but demand shocks are synchronized. Kandil and Trabelsi (2012) construct a four variables SVAR model and again they find (like many other studies) that supply shocks are not correlated but demand shocks are more or less correlated.

This study draws from recent studies on the GCC price level and inflation (Hasan and Nakibullah, 2015, and Nakibullah, 2016). These studies argue that oil price has direct and indirect impact on aggregate demand and supply of these countries. Thus, it is important to include oil price in the SVAR model to identify structural shocks of these countries. Structural shocks thus identified produce results which are quite different from other studies mentioned above. The correlations of supply shocks are dismal and they are not synchronized as found in other studies. However, in contrast to other studies, demand shocks are also not synchronized. If synchronization of supply and demand shocks is a kind of guideline in forming GMU, results of this study are not very favorable to it. 


\section{References}

Abu-Qarn, A. S., \& S. Abu-Bader. (2008). On the Optimality of a GCC Monetary Union: Structural VAR, Common Trends, and Common Cycles Evidence. World Economy, 31(5), 612-630. http://dx.doi.org/10.1111/j.1467-9701.2008.01096.x

Alshehry, A., \& S. B. Slimane. (2013). On the Optimality of GCC Monetary Union: Asymmetric Shocks Assessments. Review of Economics and Finance, 3, 49-62.

Benbouziane, M., A. Benhabbib, \& A. Benamaar. (2010). Could GCC Countries Achieve an Optima Currency Area? The Middle East Development Journal, 2(2), 203-227. http://dx.doi.org/10.1142/S179381201000023X

Beyer, A., J. Doomik, \& D. F. A. Hendry. (2001). Constructing Historical Euro-Zone Data. Economic Journal, 111(469), 102-121. http://dx.doi.org/10.1111/1468-0297.00601

Blanchard, O. J., \& D. Quah. (1989). The Dynamic Effects of Aggregate Demand and Supply Disturbances. American Economic Review, 79(4), 655-673.

Buiter, W. H. (2008). Economic, Political, and Institutional Prerequisites for Monetary Union Among the Members of the Gulf Cooperation Council. Centre for Economic Policy Research (CEPR), Citigroup NY, New York.

Espinoza, R., \& A. Senhadji. (2011). How Strong are Fiscal Multipliers in the GCC? An Empirical Investigation, IMF Working Paper, WP/11/61, Washington, D.C.

Fasano, U. (2003). Progress Toward Economic Integration and Convergence Among GCC Countries. In Fasano, U. (Ed.), Monetary Union among Member Countries of the Gulf Cooperation Council, IMF Occasional paper No.223, Washington D.C.

Hasan, M., \& A. Nakibullah. (2015). Price Level and Inflation in the GCC Countries. International Review of Economics and Finance, 39, 239-252. http://dx.doi.org/10.1016/j.iref.2015.04.008

Houssa, R. (2008). Monetary Union in West Africa and Asymmetric Shocks: A Dynamic Structural Factor Model Approach. Journal of Development Economics, 85, 319-347. http://dx.doi.org/10.1016/j.jdeveco.2006.05.003

Kandil, M., \& M. Trabelsi. (2012). Is the Announced Monetary Union in GCC Countries feasible? A Multivariate Structural VAR Approach. Middle East Development Journal, 4, 1-18. http://dx.doi.org/10.1142/S1793812012500010

Louis, R., F. Balli, \& M. Osman. (2012). On the Feasibility of Monetary Union among Gulf Cooperation Council (GCC) Countries: Dose the Symmetry Shocks Extend to the Non-Oil Sector. Journal of Economics and Finance, 36(2), 319-334. http://dx.doi.org/10.1007/s12197-010-9121-3

Mundell, R. (1961). A Theory of Optimum Currency Areas. American Economic Review, 51(4), 657-665.

Nakibullah, A. (2011). Monetary Policy and Performance of the oil-exporting Gulf Cooperation Council Countries. International Journal of Business and Economics, 10(2), 139-157.

Nakibullah, A. (2016). Impacts of Foreign and Domestic Structural Shocks on Consumer Prices of the GCC Countries. Research in World Economy, 7(2). http://dx.doi.org/10.5430/rwe.v7n2p34

Rose, A. (2000). One Money, One Market: The Effect of Common Currencies on Trade. Economic Policy, 30, 9-45. http://dx.doi.org/10.3386/w7432

Rose, A. (2009). Panel Statement. In Mackowiak, Mongellu, Noblet, and Smets (Eds.), The Euro at Ten - Lessons and Challenges. ECB, Frankfurt am Main, Germany.

Santos Silva, J. M. C., \& S. Tenreyro. (2010). Currency Unions in Prospect and Retrospect. Annual Review of Economics, 2, 51-74. http://dx.doi.org/ 10.1146/annurev.economics.102308.124508

Schaechter, A. (2003). Potential Benefits and Costs of a Common Currency for GCC Countries. In Fasano, U. (eds.), Monetary Union among Member Countries of the Gulf Cooperation Council, IMF Occasional paper No.223, Washington D.C.

Shebeb, B. (2016). Perspectives on the GCC Monetary Union. Applied Economics and Finance, 3(1), 54-63. http://dx.doi.org/10.11114/aef.v3i1.1218

Sturm, M., J. Strasky, P. Adolf, \& D. Peschel. (2008). The Gulf Cooperation Council Countries Economic Structures, Recent Developments and Role in the Global Economy, Occasional Paper Series No. 92, European Central Bank.

Summers, R., \& A. Heston. (1991). The Penn World Table (Mark 5): An Expanded Set of International Comparisons, 1950-1988. Quarterly Journal of Economics, 106(2), 327-68. http://dx.doi.org/10.2307/2937941

World Bank. (2015). Global Economic Prospects, Chapter 4, January, 155-167. 